\title{
Impact of the Four-Hour Rule/National Emergency Access Target policy implementation on emergency department staff: A qualitative perspective of emergency department management changes
}

\author{
Shizar NAHIDI, ${ }^{1,2}$ Roberto FORERO (1), ${ }^{1,2}$ Nicola MAN, ${ }^{1,2}$ Mohammed MOHSIN, ${ }^{3,4}$ Gerard FITZGERALD, ${ }^{5}$ \\ Ghasem (Sam) TOLOO, ${ }^{5}$ Sally MCCARTHY (D), ${ }^{6,7}$ Nick GIBSON, ${ }^{8}$ Daniel FATOVICH (1) ${ }^{9,10,11}$ and \\ David MOUNTAIN ${ }^{1},{ }^{11,12}$ on behalf of the 4HR/NEAT Partnership Grant*

\begin{abstract}
${ }^{1}$ Simpson Centre for Health Services Research, South Western Sydney Clinical School, The University of New South Wales, Sydney, New South Wales, Australia, ${ }^{2}$ Ingham Institute for Applied Medical Research, Sydney, New South Wales, Australia, ${ }^{3}$ Psychiatry Research and Teaching Unit, South Western Sydney Local Health District, Sydney, New South Wales, Australia, ${ }^{4}$ School of Psychiatry, Faculty of Medicine, The University of New South Wales, Sydney, New South Wales, Australia, ${ }^{5}$ School of Public Health and Social Work, Queensland University of Technology, Brisbane, Queensland, Australia, ${ }^{6}$ Prince of Wales Clinical School, The University of New South Wales, Sydney, New South Wales, Australia, ${ }^{7}$ Emergency Care Institute, Agency for Clinical Innovation, Sydney, New South Wales, Australia, ${ }^{8}$ School of Nursing and Midwifery, Edith Cowan University, Perth, Western Australia, Australia, ${ }^{9}$ Centre for Clinical Research in Emergency Medicine, Harry Perkins Institute of Medical Research, Perth, Western Australia, Australia, ${ }^{10}$ Emergency Department, Royal Perth Hospital, Perth, Western Australia, Australia, ${ }^{11}$ Division of Emergency Medicine, Faculty of Health and Medical Sciences, The University of Western Australia, Perth, Western Australia, Australia, and

${ }^{12}$ Emergency Department, Sir Charles Gairdner Hospital, Perth, Western Australia, Australia
\end{abstract}

\begin{abstract}
Objective: It has been 10 years since the ACEM Access Block Solutions Summit and 5 years since the introduction of the Four-Hour Rule/ National Emergency Access Target (4HR/NEAT) policy. The impact of this policy on ED management and on ED staff has been poorly understood. The aim of the present study was to identify changes in ED management resulting from the policy based on ED staff experiences.

Methods: Semi-structured interviews were conducted and transcribed, imported to NVivo 11 and analysed

using a combination of content, thematic analysis and phenomenological focus within a theoretical framework known as the 'logic model'.

Results: One hundred and nineteen ED staff participated in 2015-2016 to assess the impact of the policy implementation. Participants were drawn from 16 EDs in New South Wales, Queensland, Western Australia and Australian Capital Territory. In relation to ED management, three themes were identified: changes in ED management; activities and changes driven by the hospital in relation to 4HR/NEAT; and
\end{abstract}

Correspondence: Dr Roberto Forero, Simpson Centre for Health Services Research, South Western Sydney Clinical School, The University of New South Wales, Sydney, NSW 2170, Australia. Email: r.forero@unsw.edu.au

Shizar Nahidi, MD, PhD, Project Officer; Roberto Forero, MA, MPH, PhD, Senior Research Fellow; Nicola Man, BVSc, BSc (Vet), PhD, Research Fellow; Mohammed Mohsin, MS (Statistics), MSc (Demography), PhD, Senior Research Statistician; Gerard Fitzgerald, MD, FACEM, FRACMA, Professor of Public Health; Ghasem (Sam) Toloo, BA, MA, PhD (Sociology), Research Fellow; Sally McCarthy, MBBS, FACEM, MBA, Associate Professor; Nick Gibson, PhD, RN, RM, FACN, Senior Lecturer; Daniel Fatovich, MBBS, FACEM, Professor of Emergency Medicine; David Mountain, MBBS, FACEM, Associate Professor Emergency Medicine.

*Membership of the 4HR/NEAT Rule Partnership Grant list is available in the Acknowledgements section.

Accepted 25 July 2018

\section{Key findings}

- Very few studies have reported the impact of 4HR/NEAT policy on ED staff perceptions and work environment.

- Qualitative research can provide valuable information about changes generated by a time target, such as the 4HR/NEAT policy on staff working in ED.

- Policy implementation impacts may be categorised by their effect on resources, activities and outcomes.

- ED staff are sensitive and aware of how policy changes such as 4HR/NEAT have had both positive and negative impact on their working environment.

- The biggest insight from the present study is that ED management is complex and the policy generated multiple positive and negative changes demonstrating the wide range of processes involved in ED management. 
participant experiences in relation to policy compliance by staff.

Conclusions: Policy implementation is a complex process that had both positive and negative consequences on how ED staff managed the implementation of the 4HR/NEAT policy and how it changed their work environment. Understanding the perceptions of staff involved in policy implementation has significance for the design of future implementation strategies. The biggest insight from the present study is that ED management is very complex and the policy generated multiple positive and negative changes demonstrating the wide range of processes involved in this area of health services research.

Key words: emergency department management, Four-Hour Rule, National Emergency Access Target, qualitative research, staff perception and experience.

\section{Introduction}

The Four-Hour Rule, also known as the National Emergency Access Target (4HR/NEAT), was introduced in Australia to address problems such as ED overcrowding and access block. ${ }^{1-4}$ It has been 10 years since the national access block solutions summit took place in Melbourne. ${ }^{5,6}$ The summit concluded that access block for admitted patients is the principal cause of ED overcrowding, and is mainly the result of a lack of inpatient bed capacity throughout the health system. It also identified that contrary to some perceptions, it was not caused by inappropriate presentation by patients who could and should have attended a general practitioner. Overcrowding is strongly associated with excessive numbers of admitted patients being kept in the ED, rather than patients being discharged from $\mathrm{ED}$, and hence the principal causes of, and solutions for, overcrowding in ED lay outside the ED. ${ }^{5,6}$

Since then, time targets have been implemented in Australia ${ }^{7}$ and New Zealand. $4,8,9$ This 4HR/NEAT policy (instead of '4HR/NEAT policy' hereafter used 'Policy') has led to extensive redesign approaches and reconfiguration of emergency care, resulting in positive ED flow and time management changes. ${ }^{10-14}$ However, there have been limited studies on how this Policy affected those who work within the ED and are most impacted by the Policy. The aim of the present study was to provide new insights on how ED management was affected by the Policy.

\section{Methods}

As described in the previously published description of the methodology ${ }^{15}$ we used multiple sampling techniques - including quota, criterion-based and maximum variation strategies - in the ED to select 119 ED staff working across 16 metropolitan hospitals in Australia (six in New South Wales [NSW], two in the Australian Capital Territory [ACT], four in Queensland [QLD] and four in Western Australia [WA]). Among the study participants, $48 \%$ were male, $18 \%$ were directors, $36 \% \mathrm{ED}$ physicians, $37 \%$ nurses and $9 \%$ clerical staff; $44 \%$ were from NSW/ACT, $31 \%$ from QLD and $25 \%$ from WA. Thematic analysis was used to identify key issues and experiences that participants reported in relation to $\mathrm{ED}$ management. A phenomenological approach was also used for describing and interpreting participant accounts, as they may have reported a range of subjective experiences in relation to ED management changes. ${ }^{16,17}$

In order to generate a new understanding of the context and impact of the Policy, a theoretical framework was used to support the analysis. We selected a systematic evaluation of 'logic model', developed by the Kellogg Foundation and other investigators, ${ }^{18-20}$ to evaluate the Policy implementation process by categorising and interpreting the emergent themes and concepts associated with ED management.

Data management, coding and analysis were conducted using NVivo 11.

\section{Results}

Figures 1 and 2 illustrate a summary of the findings. Figure 1 reports the three principal themes identified: (i) additional resources required to aid policy implementation; (ii) novel activities implemented; and (iii) new outputs reported by participants.

The total number of citations for each component of the model is illustrated in Figure 2, in terms of resources and challenges, activities driven by the Policy and outcomes related to policy compliance.

According to Figures 1 and 2, the following three themes emerged based on the total number of citations between planned work and intended results at the different stages of the Policy implementation.

\section{Theme 1: resources required and challenges encountered during Policy introduction}

The main resources required in relation to Policy introduction and management were: changes in management, education and staff training focussed on the Policy, and financial incentives.

\section{Changes in management approach}

Participants indicated that a productive and thorough change in management approach was necessary at the introduction and during implementation of the Policy. This was because the majority of Policy-associated changes required an oversight of the whole hospital, not just the ED. Participants also suggested that careful pre-planning, adequate staffing and efficient communication (within ED and between ED and other departments) were essential to make sustainable changes. Some participants also indicated that understanding the culture and perspectives of other wards were requirements for incorporating effective change management plans. Participants also indicated that some ED environments mandated ED staff to get used to process changeover and made it relatively easy to introduce change management plans. They indicated that this implementation allowed them to pioneer Policy changes and set an example for other wards. 


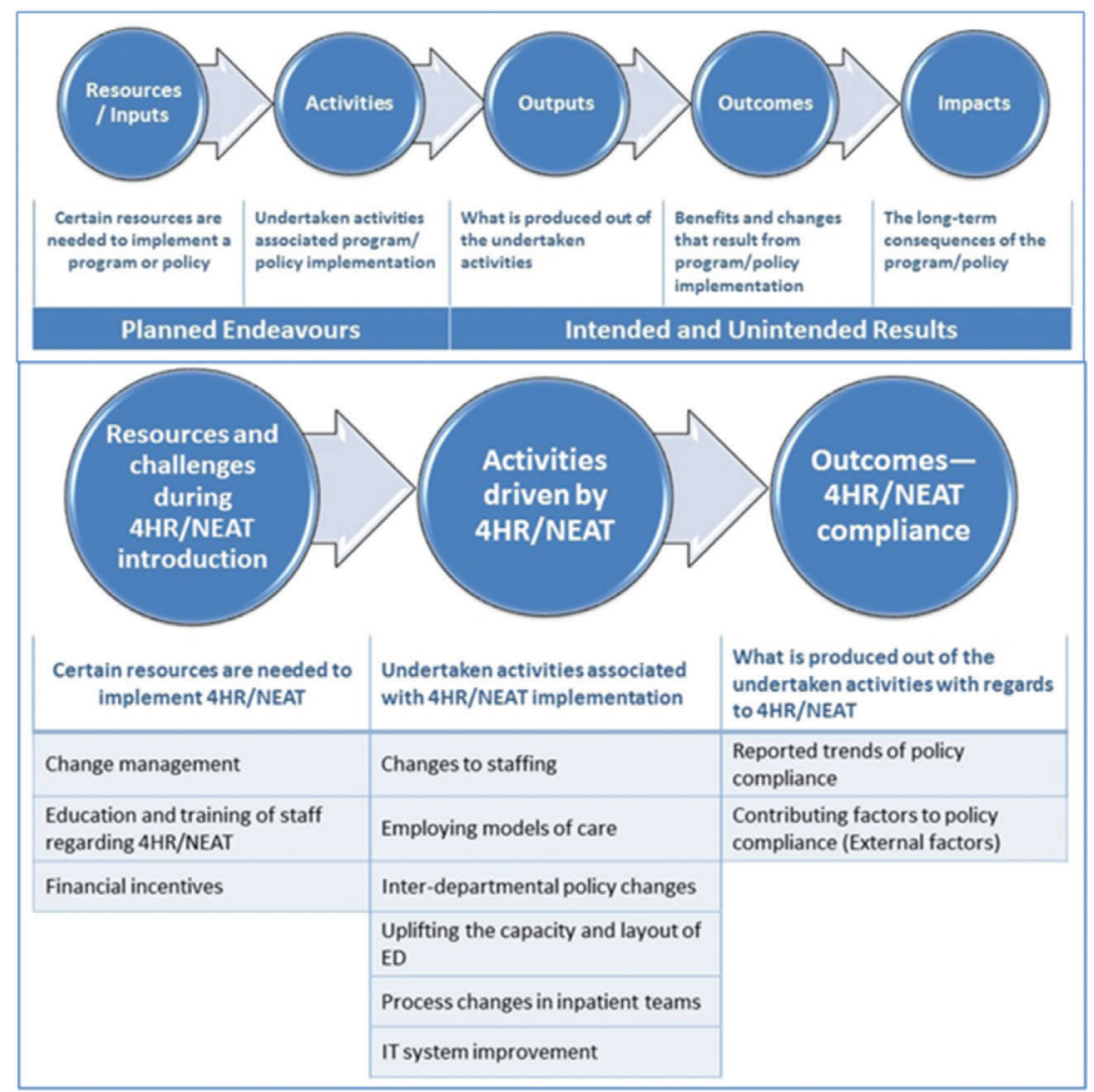

Figure 1. Adapted logic model framework for health programme and policy implementation using the main themes related to ED management.

\section{Education and staff training regarding the Policy}

Participants indicated that both ED and non-ED staff needed to be fully oriented prior to introduction. This orientation should focus on what the policy was, how it was supposed to change current practice and how it should be portrayed in practice. Some participants suggested that a thorough education strategy about the Policy was essential for effective policy implementation. Participants noted that 'one size does not fit all' was appropriate for a successful policy implementation. They agreed that the policy needs to be adapted to each individual hospital with sufficient local engagement of hospital and ED staff. A number of participants reported that their ED did not encourage effective local engagement from all levels of staff, while others reported effective local engagement and collaboration with the rest of their hospital. They also indicated that ineffective engagement with staff was related to the 'punitive approach' used in some hospitals to implement the Policy.

\section{Financial incentives}

Despite activity-based funding being linked to 4HR/NEAT compliance at the beginning of the policy implementation, some participants indicated that their ED funding was not affected by penalties or direct government financial incentives for policy compliance. Some participants indicated that in their ED, Policy compliance did not have any obvious impact on their department's funding. However, other participants indicated that the withdrawal of financial incentives (which originally were part of Policy implementation) led to inadequacy of resources to catch up with increasing patient loads. Other participants suggested that the current model of hospital funding does not foster efficiency but may lead to downgrading of the quality of patient care and increasing staff stress.

\section{Theme 2: activities driven by 4HR/NEAT}

Within this theme, participants described three main activities that were driven by 4HR/NEAT. The reported changes in ED were categorised into six groups: staff changes, models of care, inter-departmental policy changes, enhancing capacity and changed layout of $\mathrm{ED}$, process changes by inpatient teams and information technology (IT) system improvement.

\section{Staff changes}

Participants described the introduction of 4HR/NEAT-related staff roles, staff shortages, rostering changes and allied health's input in ED processes. Table 1 presents a summary of the key issues reported by participants on each of the staff changes domains.

\section{Employing different models of care}

According to the participants, ED used different models of care to improve their patient flow and policy compliance. The main models of care included the use of short stay units and/or emergency medicine units (SSU/EMU), team-based care (TBC), fast track, discharge/admission streaming model, assessment units, discharge or transit lounge and one-call admission policy. Table 2 summarises these models of care as described by the participants with their perceived advantages and disadvantages.

\section{Inter-departmental policy changes}

Table 3 presents a summary of the main policies reported by participants that were adopted by their hospitals or ED to improve their 4HR/NEAT compliance.

\section{Uplifting the capacity and changed layout of ED}

Changes to the physical space of some ED were made to either increase the capacity of the department, or to enhance the efficiency within the current layout of ED. For instance, the 


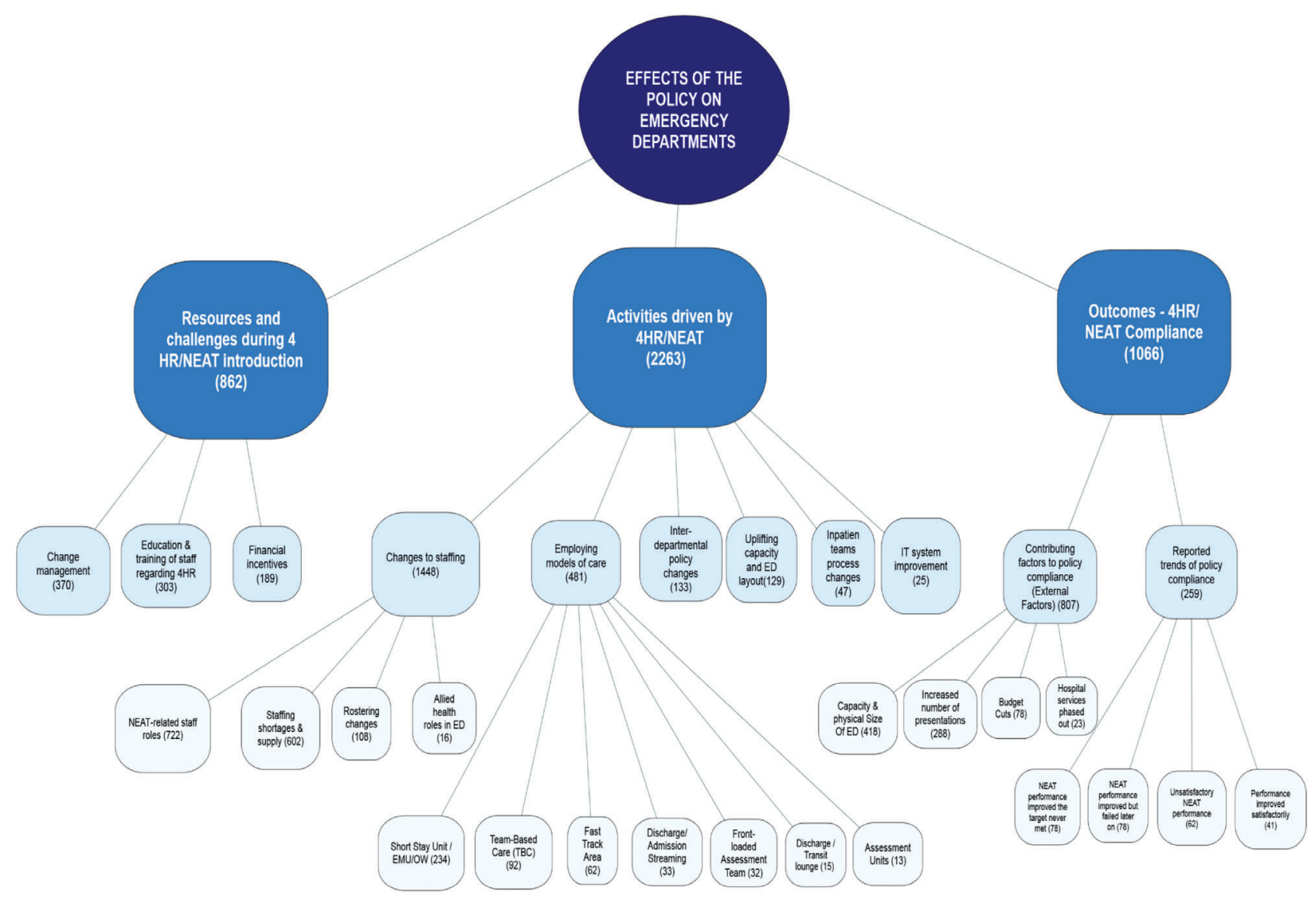

Figure 2. Number of citations per theme in relation to the perceptions reported by staff on the effects of the policy on ED management, namely resources, activities and outcomes.

introduction of an ambulance bay and offloading area substantially helped the flow in some EDs. Waiting rooms, treatment spaces and restructuring of discharge areas allowed for better monitoring and quicker management of patients. Remodelling the subacute area gave some EDs more cubicle spaces and improved their capacity.

\section{Process changes by inpatient teams}

Changes in the handover of ED patients to the inpatient wards, and changes in the ward admission processes were examples of collaborative process changes that could help inpatient teams to contribute to improving the flow-in/flow-out and bed access for ED patients.

\section{IT system improvement}

Implementation of different IT systems, especially the ED information system during Policy implementation helped some EDs to improve flow management. Application of an electronic bed management system resulted in better management of the bed capacity in some hospitals, therefore enhanced their overall patient flow. Using an electronic-whiteboard also led to better monitoring of patient care in several EDs.

Despite all these advantages, it was believed that implementation of some ED information systems slowed down ED processes, and increased inefficiencies because of additional workload (e.g. double entries) and lack of userfriendly software applications.

\section{Theme 3: outcomes - 4HR/NEAT compliance}

Participants discussed their perceived hospital performance against the Policy targets and described four external factors contributing to policy compliance and four trends of ED compliance (Fig. 2).

\section{Reported trends in Policy compliance}

The majority of participants reported an overall improvement of their Policy compliance. However, only a few reported their compliance being satisfactory. Unsatisfactory performance was related to factors such as insufficient inpatient capacity; lack of ED staff's authority over the admission of patients; insufficient logistics or professional network support from the backend of the hospital; increasing number of ED presentations; and impaired motivation of ED staff to work towards the target.

Different trends of compliance along the trajectory of Policy implementation were identified. The dominant comment made by participants was that Policy performance improved but the target has never been met. The second trend of comments suggested that 4HR/NEAT performance improved initially but failed later. The failed or 
TABLE 1. Summary of reported changes in staffing and key findings on each domain

\author{
Domains of \\ staff changes Key findings
}

Introducing 4HR/ Major changes were in relation to creating or introducing new/existing nursing roles or changing the NEAT-related responsibilities of some existing nursing roles

staff roles

These were aimed to expedite discharges, manage bed capacity and provide extra administrative support and help in subacute areas (and other clinical areas of need)

New nursing roles included positions such as '4HR/NEAT Co-ordinator', 'Navigator Nurse', 'Bed Manager', 'Waiting-Room Nurse', and '4HR/NEAT Project Officer'

New roles were mainly identified to be efficient in improving ED flow and overall 4HR/NEAT figures

Some of these were ceased due to budget constraints or lack of financial resources

Some hospitals introduced 'duty officer' (also known as 'duty consultant'), a senior medical staff who had managerial oversight of the department, and could lead the 'Quick Assessment area', the 'holding bay area' and the 'pods'

Emergency Physician in Charge (EPIC) or the Operations Manager (Ops Manager) where some of the key medical staff mentioned to assist with flow management (e.g. taking the admitting calls, collecting details and recording the data) besides their clinical duties

Staff shortages and supply

Having insufficient number of staff on the floor, and complex team structure (e.g. senior versus junior or nursing versus medical staff ) were key issues reported by participants

Participants considered that despite having both nursing and medical staff increased since 4HR/NEAT implementation, staff supply was not sufficient and remained a dominant issue for them

Proper staff ratio (nursing, medical and support staff) and differing level of experience in ED staff (i.e. juniors and seniors ED staff) were reported as important contributing factors to patient ED flow

Some participants suggested that disproportionate levels of senior and junior ED staff to task-force demands, and staff mix issues contributed to ED overcrowding

Staff mix was balanced at the early stages of 4HR/NEAT implementation, but it worsened due to staff cuts

Few participants perceived that their respective ED were well-staffed and only one hospital was mentioned to arrange staff mix according to peak-hour demands

Rostering

changes

The main drive for rostering changes in ED were either to improve patient flow during the peak hours or to cope with staff shortages. Most rostering changes occurred within medical staff

Some participants indicated that some specific changes to the layout and geographical design of ED and the adoption of team-based care mandated changes to ED staff rostering

Coverage of staff specialists over weekends boosted the overall performance of ED

Changes to the duration of medical staff shifts (i.e. change in to the 12-h or the eight-hour shifts) were reported satisfactory

Allied health's input in ED

Increased number of staff in different allied health services expedited the admission or discharge of ED patients and overall patient flow

processes

Improved flow was tangible in hospitals where modifications to ancillary services were made in line with general requirements of the cohort of admitted patients

plateaued trend in compliance was considered to be related to losing the pressure and motivation to continue to work towards the target when the federal health authorities backed off the target.

A small group of participants reported that compliance was satisfactory because of sufficient logistic support (bed capacity/geographic sufficiency); employing the whole of hospital approach; adopting efficient models of care; or having an engaging and coherent team in their ED. Despite these, some of these participants doubted that their satisfactory performance would be sustainable in the long term.

\section{Contributing external factors to policy compliance}

Participants reported that there were other factors out of their ED's control that contributed to ED policy compliance. These included the following:

Limited capacity and physical size of the ED. This was described as an 
TABLE 2. Summary of employed models of care, advantages and disadvantages of their effects on ED staff

\begin{tabular}{|c|c|c|c|}
\hline Model of care & Definition & Advantages (effects on ED) & Disadvantages of the model \\
\hline $\begin{array}{l}\text { Short stay units } \\
\text { (SSU)/emergency } \\
\text { medicine units } \\
\text { (EMU) }\end{array}$ & $\begin{array}{l}\text { SSU/EMU are inpatient units, } \\
\text { managed by ED staff, } \\
\text { designated and designed for } \\
\text { the short term (generally up to } \\
24 \text { h) treatment, observation, } \\
\text { assessment and reassessment } \\
\text { of patients initially triaged } \\
\text { and assessed in the ED } \text { ED }^{23}\end{array}$ & $\begin{array}{l}\text { Created capacity in the } \\
\text { department } \\
\text { Moderated the admissions for } \\
\text { ED-appropriate patients } \\
\text { Moderated the admissions for } \\
\text { ED-appropriate patients } \\
\text { Improved SSU/EMU's clinical } \\
\text { environment optimised the } \\
\text { functionality and efficiency } \\
\text { Implementation of strict SSU } \\
\text { admission criteria led to } \\
\text { improvements in } 4 \mathrm{HR} / \mathrm{NEAT} \\
\text { compliance }\end{array}$ & $\begin{array}{l}\text { 'Failed-to-discharge' patients were } \\
\text { transferred to SSU/EMUs for } \\
\text { the sake of stopping the clock } \\
\text { (gaming) } \\
\text { SSU admissions may have } \\
\text { miss-represented the overall } \\
\text { admission data of the hospital } \\
\text { Failed to provide optimal privacy } \\
\text { and comfort for patients } \\
\text { Decreased the capacity of their } \\
\text { sub-acute area }\end{array}$ \\
\hline $\begin{array}{l}\text { Team-based } \\
\text { care }(\mathrm{TBC})\end{array}$ & $\begin{array}{l}\text { In TBC model, usually a senior } \\
\text { medical officer works with } \\
\text { junior medical/nursing staff to } \\
\text { support prompt assessment, } \\
\text { investigations, and disposition } \\
\text { decisions }^{13}\end{array}$ & $\begin{array}{l}\text { Led to fair distribution of the } \\
\text { workload and responsibilities } \\
\text { Boosted the ED teamwork by } \\
\text { creating motivation, improving } \\
\text { morale and advancing the } \\
\text { structure and formality in ED } \\
\text { teams } \\
\text { Maintained the same level of ED } \\
\text { performance over } 24 \mathrm{~h} \\
\text { Enhanced the overall } \\
\text { sustainability and continuity of } \\
\text { care }\end{array}$ & $\begin{array}{l}\text { The model was undermined by } \\
\text { insufficient number and } \\
\text { combination of staff } \\
\text { The model was perceived to be an } \\
\text { inefficient use of nursing staff's } \\
\text { time } \\
\text { The model generated ambiguity } \\
\text { about the distribution of } \\
\text { nursing staff across } \\
\text { departments } \\
\text { The model was fragile due to } \\
\text { rapid fluctuations of ED patient } \\
\text { flow }\end{array}$ \\
\hline $\begin{array}{l}\text { Fast tracking/ } \\
\text { ambulatory } \\
\text { care/urgent } \\
\text { care centre }\end{array}$ & $\begin{array}{l}\text { Fast track is a dedicated area in } \\
\text { the ED to treat ambulant, } \\
\text { non-complex (single system } \\
\text { problem) patients who can be } \\
\text { discharged within } 2 \mathrm{~h}^{24}\end{array}$ & $\begin{array}{l}\text { Reduced ED overcrowding and } \\
\text { access block by freeing up beds } \\
\text { Led to efficient use of ED space } \\
\text { and could improve discharge } \\
\text { performance }\end{array}$ & $\begin{array}{l}\text { Some patients are mistakenly } \\
\text { triaged to these areas }\end{array}$ \\
\hline $\begin{array}{l}\text { Front-loaded } \\
\text { assessment/ } \\
\text { rapid } \\
\text { assessment } \\
\text { team (RAT) }\end{array}$ & $\begin{array}{l}\text { Front-load assessment/RAT } \\
\text { assesses patients after } \\
\text { presentation, creates initial } \\
\text { treatment plans and begins } \\
\text { appropriate treatment }{ }^{25}\end{array}$ & $\begin{array}{l}\text { Increased ED efficiency and led to } \\
\text { high-quality patient care }\end{array}$ & $\begin{array}{l}\text { Could compromise patient } \\
\text { assessments - junior doctors be } \\
\text { misguided by hasty/wrong } \\
\text { decisions from time-constrained } \\
\text { senior staff } \\
\text { Inefficient use of senior staff's } \\
\text { clinical skills } \\
\text { Undermined training and } \\
\text { education of junior staff } \\
\text { Could promote over-investigation }\end{array}$ \\
\hline $\begin{array}{c}\text { Discharge/ } \\
\text { admission } \\
\text { streaming }\end{array}$ & $\begin{array}{l}\text { This model worked through } \\
\text { division of patients (whether } \\
\text { administratively or physically) } \\
\text { into discharge or admission } \\
\text { streams, which could } \\
\text { fast-track the patients through } \\
\text { the department }{ }^{26-28}\end{array}$ & $\begin{array}{l}\text { Improved patient care in the } \\
\text { pre-triage stage } \\
\text { Required wards engagement to } \\
\text { make a progress } \\
\text { Functional Discharge Stream } \\
\text { could offset the issues in } \\
\text { admission stream - e.g. moving } \\
\text { out complicated patients from } \\
\text { subacute streams improved } \\
\text { flow in discharge stream }\end{array}$ & \\
\hline
\end{tabular}


TABLE 2. Continued

\begin{tabular}{|c|c|c|c|}
\hline Model of care & Definition & Advantages (effects on ED) & Disadvantages of the model \\
\hline $\begin{array}{l}\text { Medical/ } \\
\text { surgical } \\
\text { assessment } \\
\text { units } \\
\text { (MAU/SAU) }\end{array}$ & $\begin{array}{l}\text { Model of care involving direct } \\
\text { referral to another provider } \\
\text { would be the ideal patient } \\
\text { journey for those patients } \\
\text { who need care, but do not } \\
\text { require emergency care }\end{array}$ & $\begin{array}{l}\text { Increased patient throughput } \\
\text { through a collaborative } \\
\text { framework } \\
\text { Buffered the pressure and } \\
\text { pushbacks from the wards and } \\
\text { inpatient teams } \\
\text { Served for medical/surgical } \\
\text { patients a more focused } \\
\text { assessment }\end{array}$ & \\
\hline $\begin{array}{l}\text { Discharge or } \\
\text { transit } \\
\text { lounge }\end{array}$ & $\begin{array}{l}\text { Transit lounges were areas } \\
\text { providing a location for } \\
\text { patients to wait in beds } \\
\text { pending availability of a ward } \\
\text { bed. Participants referred to } \\
\text { overnight staging posts } \\
\text { between ED and wards, where } \\
\text { patients were ticked off the } \\
\text { 4HR/NEAT target but were } \\
\text { cared for overnight by } \\
\text { inpatient teams before being } \\
\text { admitted to the ward the next } \\
\text { day }^{29}\end{array}$ & $\begin{array}{l}\text { Urged the hospital administration } \\
\text { to evolve the model into a } \\
\text { medium to discharge the low } \\
\text { acuity patients to the wards } \\
\text { Transit lounge performance } \\
\text { compensated for the low } \\
\text { figures of other streams }\end{array}$ & $\begin{array}{l}\text { Compromised patient safety and } \\
\text { quality of care } \\
\text { Required optimal staff mix and } \\
\text { supply } \\
\text { Hindered patient flow through } \\
\text { ED } \\
\text { Required geographical proximity } \\
\text { to the ED }\end{array}$ \\
\hline
\end{tabular}

inadequate bed base to properly accommodate the patients in the ED. In several hospitals, 4HR/NEAT compliance was undermined by insufficient capacity and physical layout of their ED. However, pre- or post-4HR/NEAT renovations and redesigns to increase the size of $\mathrm{ED}$ were acknowledged in a majority of EDs.

Budget cuts. Participants indicated that some hospitals struggled with budget cuts at different levels (state, federal or hospital level) during 4HR/NEAT implementation. Participants associated the government level budgetary reforms with their staff shortage and ceasing the funding for some of 4HR/NEAT-driven roles.

Increased number of ED presentations. Participants indicated that this may have exacerbated some problems such as access block and ED overcrowding, thus hindering ED compliance. Some participants mentioned that ED may be dealing with increased numbers of low acuity and complex presentations, in particular, elderly patients or patients from culturally and linguistically diverse backgrounds. Furthermore, physical improvements driven by $4 \mathrm{HR} / \mathrm{NEAT}$ could have encouraged more people to attend ED.

Hospital services being phased out. Some participants indicated that removal of medical wards and insufficient inpatient services to meet patient presentation demands could have adversely affected Policy compliance, because it generated, at the same time, more workload regarding hospital transfers and more patients requiring admission.

\section{Discussion}

The present study presents key information based on the logic model to describe the resources needed by ED staff to implement changes associated with $4 \mathrm{HR} / \mathrm{NEAT}$ policy, the multiple activities that the policy may have generated and the outcomes perceived by participants as critical for the success and/or failure of the policy implementation.
Previous research has reported benefits and disadvantages of introduction and assimilation of timebased targets in ED. 4,6,21 Our findings have confirmed that change in management practices was necessary at the introduction and during implementation of the policy, because the majority of the Policyassociated changes required an oversight of the whole hospital, not just the ED. In addition, our findings indicated a substantial number of activities were required during the introduction and implementation of the Policy. These are consistent with the application of logic modelling as a management and learning tool in other areas and provide tools in determining what is working well and what is not. ${ }^{18-20}$

Findings of this qualitative research suggest that ED staff have a diverse range of perceptions and experiences about how the Policy changed their local ED environment. As the main themes emerged, it turned out that the changes reported during the introduction of the Policy 
TABLE 3. Summary of reported policies, their definition, effects and disadvantages

\begin{tabular}{|c|c|c|c|}
\hline Policy & Definition & Effects on ED & Disadvantages \\
\hline $\begin{array}{l}\text { One-call } \\
\text { admission } \\
\text { policy }\end{array}$ & $\begin{array}{l}\text { A hospital-wide policy that } \\
\text { hypothetically gave ED the } \\
\text { power to call a ward and } \\
\text { inform them of a patient } \\
\text { admission, without needing to } \\
\text { negotiate about admitting the } \\
\text { patient }\end{array}$ & $\begin{array}{l}\text { Empowered ED staff by giving } \\
\text { them authority in deciding on } \\
\text { patient's in-hospital journey }\end{array}$ & $\begin{array}{l}\text { Policy did not improve their } \\
\text { 4HR/NEAT compliance } \\
\text { Did not resolve the tensions } \\
\text { between ED and inpatient } \\
\text { teams }\end{array}$ \\
\hline $\begin{array}{l}\text { Over-census } \\
\text { policy }\end{array}$ & $\begin{array}{l}\text { The policy was based on the } \\
\text { premise that having one extra } \\
\text { patient on a ward would be } \\
\text { safer than managing several } \\
\text { extra patients in ED who are } \\
\text { waiting for beds }\end{array}$ & $\begin{array}{l}\text { Empowered ED to foster changes in } \\
\text { different care processes delivered } \\
\text { by inpatient teams }\end{array}$ & $\begin{array}{c}\text { Could not change the teamwork } \\
\text { behaviour in in-patient teams }\end{array}$ \\
\hline $\begin{array}{l}\text { Escalation } \\
\text { policy }\end{array}$ & $\begin{array}{l}\text { This policy mandated the } \\
\text { response from the rest of the } \\
\text { hospital when ED was getting } \\
\text { full }\end{array}$ & $\begin{array}{l}\text { Led to efficient management of ED } \\
\text { overcrowding and patient flow }\end{array}$ & $\begin{array}{l}\text { Perceived to be ineffective and } \\
\text { inefficient due to suboptimal } \\
\text { communications between ED } \\
\text { and the rest of the hospital }\end{array}$ \\
\hline $\begin{array}{l}\text { Direct } \\
\text { admission } \\
\text { policy }\end{array}$ & $\begin{array}{l}\text { Allowed ED to send } \\
\text { non-emergency patients } \\
\text { directly to the wards }\end{array}$ & $\begin{array}{l}\text { Discouraged the specialists to send } \\
\text { their stable patients to the wards } \\
\text { Expedited patient throughput } \\
\text { Allowed ED to take control over } \\
\text { admissions }\end{array}$ & \\
\hline $\begin{array}{l}\text { Bed } \\
\text { allocation } \\
\text { Policy }\end{array}$ & $\begin{array}{l}\text { Mandated inpatient teams to } \\
\text { pull their patients to their } \\
\text { ward }\end{array}$ & $\begin{array}{l}\text { Improved patient flow in ED where } \\
\text { a bed manager was appointed to } \\
\text { monitor hospital beds }\end{array}$ & \\
\hline
\end{tabular}

were mostly around the inputs, resources and challenges at the earlier stages of 4HR/NEAT implementation. The diverse range of activities and process changes during implementation suggested several drastic and systemic changes either at the ED level, hospital level or at the health district scale.

The main outcomes of the Policy were reported in terms of the perceived compliance with 4HR/NEAT targets. These findings are consistent with the key elements of the logic model framework widely used for evaluation and planning, which assumes that resources/inputs lead to activities and interventions that would alter the outputs/outcomes. ${ }^{18-20,22}$

These findings provide insight for stakeholders to understand the complexity and variety of $4 \mathrm{HR} / \mathrm{NEAT}$ implementation processes and changes that ED staff perceived and reported before and during Policy implementation across Australia. This has generated the following lessons for the future:

1. ED management implementation plans can be used to assess and monitor the quality of work performance in ED in the post-4HR/ NEAT era;

2. Activity-based outcomes require careful consideration if new policies are implemented in the future.

\section{Limitations}

There are several limitations to our study. The study was done after implementation of the Policy and so the findings were post hoc and we could not identify events occurring before or during implementation. Another significant limitation is that the perceptions of the policy are mainly limited to ED staff without perspectives from executives, inpatient teams or patients. As indicated in our methods published previously, we achieved a comparable coverage of the issues identified with high levels of saturation and interrater reliability. ${ }^{15}$ In addition, another important limitation was that the study was limited to four Australian jurisdictions only (i.e. NSW, ACT, QLD and WA) and did not include Victoria, South Australia, Tasmania and Northern Territory because of restrictions in the data linkage capability for the quantitative component of the project and not having associated investigators from those jurisdictions in our project and we could not include New Zealand for the latter reason.

\section{Conclusion}

Policy implementation within health systems is a complex process that has both positive and negative 
consequences. The present study provides valuable information on how ED staff managed the implementation of the 4HR/NEAT policy and how it changed their work environment, including positive and negative changes in the management approach. These positive and negative changes also effected resources and financial optimisation and generated the opportunity to implement models of care and hospital policy changes; some of them were also positive and negative.

The strategic intent behind the introduction of the policy was to decongest the ED by making performance against the target a whole of hospital or whole of system issue. As indicated in the literature, the overall experience that has been reported indicate that although the policy led to initial improvements, some of them have tended to plateau or even stagnate at levels below the performance target set by the policy., ${ }^{4,6}$, We recommend that other key performance indicators or quality of measures need to be identified such as specific models of care on discharge/admission streaming or medical assessment units in Table 2.

Understanding the perceptions of staff involved in policy implementation has significance for the design of the implementation strategy. The reality is that as the system adjusts to a new normal, the fundamental capacity limits of the system continue to challenge its performance. The most important lesson from the present study seems to be that ED management and processes are complex, and that changing policies and use of key performance indicators generate multiple changes and pressure areas, many of which are unpredictable and vary between departments. The study demonstrates the need for more holistic measures of departmental responses and the need for more varied and nuanced key performance indicators and measures of outcomes when new policies are applied.

\section{Acknowledgements}

This project was funded by the Australian National Health and
Medical Research Council (NHMRC) Partnership (grant no. APP1029492) with cash contributions from the following organisations: Department of Health of Western Australia, ACEM, Ministry of Health of NSW and the Emergency Care Institute, NSW Agency for Clinical Innovation, and Emergency Medicine Foundation, Queensland.

The following are the members of NHMRC Partnership Project APP1029492: Project Management Committee: Roberto Forero and Ken Hillman (Simpson Centre for Health Services Research, University of New South Wales, Sydney, NSW, Australia), Daniel Fatovich (Centre for Clinical Research in Emergency Medicine, Department of Emergency Medicine, Royal Perth Hospital and University of Western Australia, Perth, WA, Australia, and ACEM, West Melbourne, Victoria, Australia), Sally McCarthy (ACEM, West Melbourne, Victoria, Australia, and Emergency Care Institute, NSW Agency for Clinical Innovation, Sydney, NSW, Australia), David Mountain, Peter Sprivulis and Antonio Celenza (ACEM, West Melbourne, Victoria, Australia, and Emergency Medicine, University of Western Australia, Perth, WA, Australia), Paul Tridgell (Paul Tridgell Consulting, Sydney, NSW, Australia), Mohammed Mohsin (Psychiatry Research and Teaching Unit, SWSLHD, NSW Health, Sydney, NSW, Australia, and School of Public Health and Community Medicine, UNSW, Sydney, NSW, Australia), Frank Daly (ACEM, West Melbourne, Victoria, Australia, and South Metropolitan Health Service, Department of Health Western Australia, Perth, WA, Australia), Elizabeth Rohwedder and Sam Green (Health System Improvement Unit, Department of Health Western Australia, East Perth, WA, Australia), Sarah Marmara (NSW Ministry of Health, North Sydney, NSW, Australia), Gerard Fitzgerald (ACEM, West Melbourne, Victoria, Australia, and School of Public Health and Social Work, Queensland University of Technology, Brisbane, QLD, Australia), John Burke (ACEM, West Melbourne, Victoria, Australia, and Department of Emergency Medicine, Royal Brisbane and Women's Hospital, Brisbane,
QLD, Australia), Paul Middleton (ACEM, West Melbourne, Victoria, Australia, and Australian Resuscitation Council of NSW, NSW, Australia) and Drew Richardson (ACEM, West Melbourne, Victoria, Australia, and Australian National University Medical School and Canberra Hospital ED, Canberra, ACT, Australia); Associate Investigators: Nick Gibson (Edith Cowan University, Perth, WA, Australia), Jeffrey Braithwaite (Macquarie University, Sydney, NSW, Australia), Peter Nugus (McGill University, Montreal, Canada); Staff: Hanh Ngo (Emergency Medicine, University of Western Australia, Perth, WA, Australia), Wing (Nicola) Man, Shizar Nahidi, Josephine De Costa and Brydan Lenne (Simpson Centre for Health Services Research, University of New South Wales, Sydney, NSW, Australia), Sam Toloo (School of Public Health and Social Work, Queensland University of Technology, Brisbane, QLD, Australia).

\section{Competing interests}

GF is a member of the editorial board of Emergency Medicine Australasia. SM is a section editor for Emergency Medicine Australasia.

\section{References}

1. Fatovich DM. Access block: problems and progress. Med. J. Aust. 2003; 178: 527-8.

2. Forero R, Hillman KM, McCarthy S, Fatovich DM, Joseph AP, Richardson DB. Access block and ED overcrowding. Emerg. Med. Australas. 2010; 22: 119-35.

3. Richardson DB. Increase in patient mortality at 10 days associated with emergency department overcrowding. Med. J. Aust. 2006; 184: 213-6.

4. Ngo H, Forero R, Mountain D et al. Impact of the Four-Hour Rule in Western Australian hospitals: trend analysis of a large record linkage study 2002-2013. PLoS One 2018; 13: e0193902.

5. Forero R, McCarthy S, Hillman K. Access block and emergency department overcrowding. Crit. Care 2011; 15: 216-22. 
6. Staib A, Sullivan C, Griffin B, Bell A, Scott I. Report on the 4-h rule and National Emergency Access Target (NEAT) in Australia: time to review. Aust. Health Rev. 2016; 40: 319-23.

7. Geelhoed GC, de Klerk NH. Emergency department overcrowding, mortality and the 4-hour rule in Western Australia. Med. J. Aust. 2012; 196: 122-6.

8. Jones $\mathrm{P}$, Sopina E, Ashton $\mathrm{T}$. Resource implications of a national health target: the New Zealand experience of a shorter stays in emergency departments target. Emerg. Med. Australas. 2014; 26: 579-84.

9. Jones P, Wells S, Harper A et al. Impact of a national time target for ED length of stay on patient outcomes. N. Z. Med. J. 2017; 130: 15-34.

10. Vezyridis P, Timmons S. National targets, process transformation and local consequences in an NHS emergency department (ED): a qualitative study. BMC Emerg. 2014; 14: 12.

11. Nugus P, Forero R, McCarthy S et al. The emergency department 'carousel': an ethnographicallyderived model of the dynamics of patient flow. Int. Emerg. Nurs. 2014; 21: 3-9.

12. Directorate AGH. Annual Report 2013-2014. Canberra: Directorate AGH, 2014.

13. Stokes B. Four Hour Rule Program: Progress and Issues Review. Perth: Government of Western Australia Department of Health, 2011.
14. Ben-Tovim DI, Dougherty ML, O’Connell TJ, McGrath KM. Patient journeys: the process of clinical redesign. Med. J. Aust. 2008; 188(Suppl): S14-7.

15. Forero R, Nahidi S, De Costa J et al. Application of four-dimension criteria to assess rigour of qualitative research in emergency medicine. BMC Health Serv. Res. 2018; 18: 120 .

16. Norlyk A, Harder I. What makes a phenomenological study phenomenological? An analysis of peer-reviewed empirical nursing studies. Qual. Health Res. 2010; 20: 420-31.

17. Crotty M. The Foundations of Social Research: Meaning and Perspective in the Research Process. London; Thousand Oaks, CA: Sage Publications, 1998.

18. Kellogg WK. Using Logic Models to Bring Together Planning, Evaluation, and Action: Logic Model Development Guide. Battle Creek, MI: W.K. Kellogg Foundation, 2004.

19. McLaughlin JA, Jordan GB. Logic models: a tool for telling your programs performance story. Eval. Program Plann. 1999; 22: 65-72.

20. Hayes $\mathrm{H}$, Parchman ML, Howard R. A logic model framework for evaluation and planning in a primary care practice-based research network (PBRN). J. Am. Board Fam. Med. 2011; 24: 576-82.

21. Mason S, Mountain G, Turner J, Arain M, Revue E, Weber EJ. Innovations to reduce demand and crowding in emergency care: a review study. Scand. J. Trauma Resusc. Emerg. Med. 2014; 22: 55.

22. Wallerstein N, Duran B. Community-based participatory research contributions to intervention research: the intersection of science and practice to improve health equity. Am. J. Public Health 2010; 100: S40-6.

23. NSW Ministry of Health. Emergency Department Short Stay Units. Sydney: NSW Government, 2014.

24. NSW Ministry of Health. Emergency Department Models of Care. North Sydney: NSW Ministry of Health, 2012.

25. Edwards T. How rapid assessment at triage can improve care outcomes. Emerg. Nurse 2011; 19: 27-30.

26. Burke JA, Greenslade J, Chabrowska J et al. Two hour evaluation and referral model for shorter turnaround times in the emergency department. Emerg. Med. Australas. 2017; 29: 315-23.

27. Cameron A, Rodgers K, Ireland A, Jamdar R, McKay GA. A simple tool to predict admission at the time of triage. Emerg. Med. J. 2015; 32: 174-9.

28. Holdgate A, Morris J, Fry M, Zecevic M. Accuracy of triage nurses in predicting patient disposition. Emerg. Med. Australas. 2007; 19: 341-5.

29. Gilligan P, O'Kelly P, Hegarty D, Winder S. The transit/admission lounge study. Ir. Med. J. 2009; 102: 19-21. 